\title{
THE COMMANDER AS THE LEADER OF THE MODERN ORGANIZATION
}

\author{
Maciej MARCZYK \\ National Defence University, Warsaw, Poland \\ m.marczyk@aon.edu.pl
}

\begin{abstract}
The article author decided to examine leadership in the modern organization, its task and work environment and partly interactions which falls within the framework of its mission in the organization. Interesting from the point of view of leadership is there are features of the modern manager and answer the question whether they are compatible the characteristics of the commander in the army. Currently, the greatest emphasis in the organization is put on human behavior, its role and importance for the functioning of the company. Business administration is associated with a clear definition of areas in which management will move to a modern organization. The task of any manager or leader of our time is the most efficient use of these areas at maximum lowering costs. Most often in the literature, you can find information about the four types of resources: Human, Financial, Physical, Information.
\end{abstract}

\section{Key words: Human resource management, organization, leadership.}

\section{Introduction}

In the literature can be divided into many streams receiving a proper perspective on the contemporary organization in its people and their role in its structures. These are the concepts of psychological, sociological (classic and behavioral). Always, however, the main focus was and is on the man. Important in these theories also plays a role of leadership, management and organization relationships and hierarchical systems in the organization.

Today in organizational psychology assumes that leadership has a significant impact on the functioning of the organization. Management of the company, leading a team of human and how does this type of task affect the work and interpersonal relationships within the organization. Assuming that it has a huge impact on the health of the company and the implementation of tasks in the assembly, try to consider what should be the style of work manager in the organization and are you sure the model of military drill and absolute obedience and blind following orders are correct direction of management in an organization where there is a hierarchy and relationships of all workers among themselves like military, where often people create equal teams, working outside the workplace distributed organizations and the goal is to complete the task and not the same need to remain in the workplace as it is in a hierarchical organization.

Thus, the research problem for a manager in the organization and the question whether he has to remind the commander of the army or military leader on the model (formal or informal). How to manage your business and how to manage people would be the best for the company or the execution of the tasks facing the team.

Taking into account the above arguments author considers it reasonable to 
describe the problem of modern organization and its conductivity by a modern leader in the organization (manager). It should also raise the issue of the organization and its nature and decide on the basis of the conclusions of the study which type of manager is now needed twenty-first century organizations.

\section{Organization of the XXI century - a study of the problem}

The literature can be divided into many streams describing an organization. Of course, the most important directions have been defined by psychologists and sociologists and researchers - specialists in organization theory.

Psychological direction is based on the concept of behavioral, whose central issue is the behavior of the people in the organization. Representatives of this direction are: J. March and H.A. Simon. The direction of sociological focus on human relations, especially on the interaction or interaction at each other in social groups. Representatives of this direction are D. Mc Gregor and R. Likert.

Modern authors describing the above phenomena put an equal sign between the organization and man. R. W. Griffin argues that "the organization is a group of people who work together in an orderly and coordinated manner to achieve a set of objectives."[1]

Presented shots shows that currently the emphasis is on human behavior, its place and importance to the functioning of organized whole[2]. But the features of a modern organization developed a new known to us modern information society and remain as constant:

1. virtuality; virtual means unlimited, active, able to quickly adapt. In today's organizations, we can see that we have a tendency to create hypothetical, it really does not exist in reality structures. Employees are able to organize the working conditions and the gain they need it measures because their business is the most important achievements for which they were imposed. Currently determinant of the effectiveness of the employee is not how many sat in the workplace, but it is what he has done. A characteristic, easily discernible trend is here to dissipate power and structures of the organization,

2. gaining power, gaining confidence and plausibility against other organizations, our employees and customers. It should be related to ethics

3 . subsydiality, the employee shall have the universal right to make a mistake. The best and fastest we learn through practice and it carries with it the opportunity for mistakes. Everything has its limits.

4. role of women in the organization. It's about leveling up some differences, including imbalance in the employment of women in managerial positions in relation to the working men already there,

5. co-garde value system in the organization, by means of which exerts a significant impact on the social environment and their system of values,

6. awareness of cultural differences. Multicultural team can be extremely creative. Each of the members will have an amazing experience with its origin. Besides, you can learn a lot from others, for example. foreign companies.

7. universal tolerance, if it does not endanger the functioning of the company.

8. independence of the workers, the ability to create their own businesses, managing a modern organization is a challenge for the modern manager ".[2]

With such an in-depth analysis of the above factors, we are able to focus on the behavior of people and in this respect to analyze the functioning of the organization.

We can cite two points of view:

1. formal: to be considered that the organization is a formal structure and

2. humanistic: the most important are the people in the organization, it is thanks to them that it can function, 
The organization as a group of people interconnected horizontal or vertical interaction is much more efficient and friendly. The times at which the work manager based solely on issuing commands and endless checks rather gone. Introduction margin of error, take responsibility for subordinates, internal training meant that closer today to argue You run, you train, you reply - where the role of the manager is seen in a different way. Entering tasks, but also enforces and responsible for their implementation.

Modern organizations with increasingly complex network of teams, perform increasingly complex and specialized task. These tasks are of autonomy and instrumentality teams, which shape their own regulations and procedures specifying how the behavior of a specific type and shape of the modern manager.

Features of the manager's work has evolved over time. By involuntary modifications on the structure, the way the organization itself manager also had to retrain. Currently manager must sometimes organize the work of dozens of people in many various places. That's how this will be determined by his knowledge, experience and numerous feeling.

The person who presents the characteristics of organizations XXI century is

Prof. Z. Malara. In his view, the shape of such an enterprise consists, f.eg.:

1. increased involvement of every employee in the company, its development. It is one of the main vices, which now has a modern company.

2. open to any and all changes. Everything is constantly changing. It is difficult to operate in this type of environment, if we do not him adjust appropriately.

3. willingness to experiment. It is quite a popular phrase, which in everyday language we encounter as "do not risk, you do not earn."
4. capacity utilization of the team. With some specific opportunities and use them is a kind of "intelligence".

5. ability to avoid errors, the possible prevention. Error is a natural thing in the activities of humans and machines (because they were created by humans, so their subsequent errors are due in part to earlier human negligence).

6. ability to rapidly correct structures and respond to customer requests. Enterprises, companies have one major mission.

7. flexible to adapt to the conditions in selected markets and customer preferences.

8. ability optimistic look at the transformation.[5]

\section{The leader in the modern organization - a study of the problem}

The best prospect for the group is, of course, a combination of leadership and management of the organization, group and choice for the leader of a person endowed with the characteristics of the 'leader', or at least consciously learned. Worse when leadership is informal, ie. Features specific to 'chief' is someone with the staff of the group, which often leads to other without being a manager. Is a common situation in hierarchical groups, for example. Military - where commanders to appoint rather than elect. Appointed commander does not necessarily have the leadership qualities and the power is transmitted to him the rules. The management company may choose manager, a leader guided by the personality features or specialized education - studies, courses or training in management and leadership. Maybe that's why it is so important in the management of the organization are personal decisions or management of human capital.

According to R. W. Griffin's management system in an organization can be defined as a set of activities that embrace the full cycle management process, so planning and decision-making, 
organizing, directing and controlling human resources directed at the organization (human, financial, physical and information) and executed with a view to achieving the objective in an efficient and effective manner. Factors occurring organizations make, it is not easy to specify. This is evidenced by the various shots, which the authors seek to reduce them rather than expanding the. Therefore, it should be pointed rather to certain groups of factors that influence human behavior in organizations.

Works leader in the organization (manager) is characterized by high complexity and a fairly large area of responsibility. Important as they are, however, steps everywhere he performed and proper operating procedures. This could be, for example.

Described the procedures of the company (organization) decision-making process by the management.

According to B. Kuc can be described several stages[3]:

1. First diagnosis of the problem and its clear definition. Beginning from which much depends. When poor understanding of the problem or the wrong location the whole process loses its meaning. The results are already known to początku- it will only be an unnecessary waste of precious time.

2. Collection of this information, which is closely related to the problem. Having this type of data will allow us to analyze in depth the way a given situation. It also happens that due to the amount of information, the decision is difficult. This applies to a shortage of the necessary information as well as their excess. Getting to know all the pros and cons of the decision-maker begins simply fluctuate.

3 . Identify the cause of the problem. At this stage, we are committed to clearly identify the reasons which led to this situation. This will tell us what is the weakness of the company - from this moment is a short way to overcome the obstacle. First, we define a group of possible causes that could flow into the creation of anomalies. Then, through rigorous qualifying, analyzing all the points we choose one of them.

4. Assessment of alternative solutions. This step is based, inter alia, on an objective assessment "for and cons "of each alternative. At this stage initiates making "real" decision.

5. Selecting one solution, make a decision. Now is the moment when you should take important decisions. Of all the solutions we implement only one.

6. Implementation of the decision and the evaluation of its results. At this stage, you end up on our divagation the problem. If we were able to eliminate the obstacle, we can return to our tasks, which again go through the tedious process of decisionmaking. Sometimes, however, the action taken only worsen the problem.

Business administration is associated with a clear definition of areas which will move the management of a modern organization. The task of any manager of the new times is the most efficient use of the described areas at maximum lowering costs.

Most often in the literature, you can find information about the four types of resources:

1. Human resources: these are all employees reporting directly to the head, including driver, manual workers, whitecollar, vendors, etc.. task manager is a rational distribution of tasks and responsibilities between the various collaborators,

2. Financial resources: government subsidies, earnings and investments. The area associated of financial resources. Manager must carefully analyze the costs and the perspective to look at the data phenomenon,

3. Physical resources: tools to get the job becomes easier, including office buildings, computers, shelves, office accessories. Employees should not be missing anything, of course, referring to 
things that are able to improve the performance of their work,

4. Information resources: the data needed to perform certain operations, such as sales forecasts, government publications, numerous economic statistics. Appropriate selection and analysis of certain information is important and very difficult. Requires a great deal of experience, knowledge and intuition to recognize that the information indeed we need.[4]

At present leader of the organization must play multiple roles during their term of service. Often becomes a mediator, rock and executioner. All subordinates the company's strategy and objectives which erected in front of him. What matters is the effect and not the way of the task. Manager as a manager is now responsible for two primary roles: interpersonal and informational. In the case of the first act, a person performing managerial functions sometimes unintentionally occur as a representative. Literally outside of designated areas of work he is a champion of the company. Must his behavior and manners to show that his company is at a high level. Managerial position was established mainly because by with the help of various orders and paragraphs, to be able to guide others. Subordinates show the direction and the way they operate. As a broker (connector) is required to work closely with the company's environment.

While performing the role of information acts as spokesperson, promoter, an expert specialist. These are the dimensions, in which the key role played by communication between people, work in a team. With the role of representative, he is able to effectively select only the information that example. Shall have the right and can get outside areas of the organization. As a promoter of a person occurs in the form of unlimited knowledge. That he shows colleagues plan. In case of any ambiguities or problems he just is obliged to them as soon as possible solutions. Linked to this is the role of the expert and specialist who may have the knowledge base to decide the case [4].

Consequences of our actions may appear only after some time. It is difficult to predict what the consequences will be carried with it some of the seemingly simple decision. Often managers, not knowing how to act, how to decide, decide to listen to your inner voice - intuition (hope that their intuition does not fail). Determine what intuition is very difficult, with the experience and knowledge gained over the years man unknowingly taking a number of thought processes. Their effect is the decision drawn from intuition. We can not talk here about the makeshift coin toss, sooner of vague internal prioritization, analysis and make the right at this moment for our decision. "There are no problems, only opportunities" - this quote clearly shows the direction in which they should now strive managers. Determination of the new goals, the continued development of this must be their properties today. Approach, in which every problem is an opportunity to demonstrate is most advisable. This is closely connected with the nature of the manager and his work. Management is nothing more than a constant risk and a big responsibility, because a positive mental attitude to each of the cases can be so important, even crucial importance to make the right decision.

The question, of course, is a leader in contemporary organizations should only and only focus on solving specific problems at work, personal or collective? His work is characterized by a constant after all, decision-making, and it is inextricably linked with the problem. The decision that is a dilemma.

What you choose to get the most benefit while cost rationalization. The modern leader should not only focus on "skipped" the next obstacle. It must first of all feel the moment, occasions, by which the organization in which they work, just reaches the intended objective (earn) or 
"reached a sufficient level of development." This type of leader is able to see the benefits of the environment. Able to listen and quickly draw conclusions and thus efficiently organize the resources of the company and focuses on new tasks and tools. The leader of the military commander is primarily that personal involvement and characteristics, is able to lead subordinates to fight 'to the death' in both room conditions (classes, activities, implementation of tasks in the unit, working behind a desk) as well as in time of war - the victim life.

Probably can not compare this type of action especially combat stress, but the finance company on the exchange earning bajońskich or grated sums are not the same stress as war. We know the cases of suicide because of bankruptcy and bankruptcy of the company, we know the spectacular advances of life and financial 'From rags to riches'. So it's hard today for unambiguous definition of leadership and characteristics of leadership in organizations such as hierarchical. Military and company active in the economy. But surely command features are useful in the management of human resources even after the 'adventure' with the military. Were often soldiers are proficient leaders of non-military organization, but it is not the rule. This does not work while in the other side. Manager, the leader of an organization can have big problems in the management of a group of soldiers, where the bad decisions pay health or life.

\section{Conclusion}

Every person who sees himself as the leader wants to achieve success. It is impossible to even find a person who would not want to be in something "best". Is this should be a contemporary leader in the organization? The manager who carefully analyzes the situation, the company also plans to develop over time (the company's future plans for several years) and an increase in profits for the period. Can we speak of a born manager, if this type of leadership should be taught for years? What should characterize such a contemporary leader in the organization, regardless of its type?

Universities around the world offer studies of broadly defined "management", assuring us that they are able to do every manager, leader (eg. MBA). But does she know enough. Acquired skills are often required features like the birth: the efficiency of insight, reflective, nuanced perception, anticipation, decision-making ability, and of course creativity. What matters is the experience and practice in the profession is difficult to say whether any university is able to so strongly interfere in our character, our intellectual capacity to really make a good manager of human future?

But the fact is that today's modern leader and the group leader should always be characterized by f.eg. features: ability to achieve the set objectives, the orientation of the work (action), ability to make quick decisions, consistency of action, ability to influence people, the need for achievement, positive and creative approach, creativity, rability to plan and organize, ability to work in a team, need to gain new experiences and personal development, interpersonal sensitivity, resistance to stress, communication skills, objectivity, ability to set high standards of work, ability to work at a certain level of detail, loyalty and support to managers and colleagues.

Enterprises of the future will be so dynamic and creative, it will need a new quality of leadership, adapting to any situation that may occur in their environment. Those which will not be easy to surprise. Will be able to provide different trends and even manipulate them. Structure of the companies will not be as bright as before. Characterize it will be extended communication channels and decision-making. More and more people will have an impact on what happens in the enterprise. 
Everyone will get their "five minutes", since it will depend on how effectively use its chance. Will be the end of the bureaucratic burden. Many decisions will be conducted in an informal way. Talk "every with each "to know as much as possible alternatives, and possible ways to solve a given problem may move to the virtual world and can be there to look for new solutions and answers to all questions. Whoever this world will be a chance in today's "rat race".

\section{References}

[1] Dyrda M., Sociology and social psychology in the management of organizations, Medium, Warsaw 2004.

[2] Griffin R.W., Fundamentals of Management organizations, PWN, Warszawa 1996.

[3] Kuc B., Perfect management, publishing executive, Helion, Gliwice 2010.

[4] Kuc B., Zarządzanie doskonate, wydawnictwo menedżerskie PTM, Warszawa 2000.

[5] Malara Z., Improving the organization and business management in theory and practice OPO, Bydgoszcz 2002. 